See discussions, stats, and author profiles for this publication at: https://www.researchgate.net/publication/297260122

\title{
Does intrasession concurrent strength and aerobic training order influence training-induced explosive strength and VO2max in prepubescent children?
}

Article in The Journal of Strength and Conditioning Research • March 2016

DOI: $10.1519 /$ JSC. 0000000000001431

CITATIONS

5

5 authors, including:

Ana Ruivo Alves

Polytechnic Institute of Beja

22 PUBLICATIONS 20 CITATIONS

SEE PROFILE

$+$

Henrique P. Neiva

Universidade da Beira Interior

85 PUBLICATIONS 273 CITATIONS

SEE PROFILE

Some of the authors of this publication are also working on these related projects:
READS

625

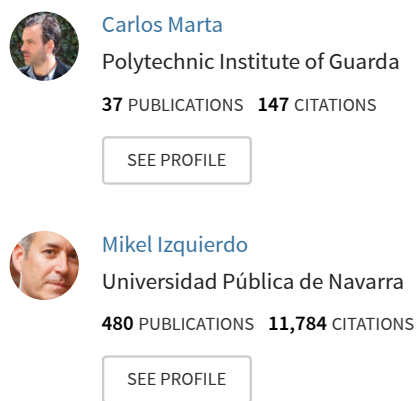

Project Inter-individual variability in response to exercise intervention or usual care in hospitalized older adults View project

Project The acute and chronic effect of Velocity-based resistance training View project 


\title{
Does Intrasession Concurrent Strength and Aerobic Training Order Influence Training-Induced Explosive Strength and $\dot{V}_{2}$ Max in Prepubescent Children?
}

\author{
Ana R. Alves, ${ }^{1}$ Carlos C. Marta,,${ }^{2,3}$ Henrique P. Neiva, ${ }^{1,4}$ Mikel Izquierdo, ${ }^{5}$ and \\ Mário C. Marques ${ }^{1,4}$ \\ ${ }^{1}$ Department of Sport Sciences, University of Beira Interior, Covilhã, Portugal; ${ }^{2}$ Department of Sport Sciences, Guarda \\ Polytechnique Institute, Guarda, Portugal; ${ }^{3}$ Research Unit for Inland Development, UDI, Guarda, Portugal; ${ }^{4}$ Research Center \\ in Sport Sciences, Health Sciences and Human Development, CIDESD, University of Trás-os-Montes and Alto Douro, Vila \\ Real, Portugal; and ${ }^{5}$ Department of Health Sciences, Public University of Navarre, Navarre, Spain
}

\begin{abstract}
Alves, AR, Marta, C, Neiva, HP, Izquierdo, M, and Marques, MC. Does intrasession concurrent strength and aerobic training order influence training-induced explosive strength and $\dot{\mathrm{V}}_{2}$ max in prepubescent children?. J Strength Cond Res 30(12): 3267-3277, 2016-The aim of this study was to analyze the interference of strength and aerobic training order over an 8-week period on explosive skills and maximal oxygen uptake $\left({ }^{\mathrm{V}} \mathrm{O}_{2}\right.$ max $)$ in prepubescent children. One hundred twenty-eight prepubescent children aged 10-11 years (10.9 \pm 0.5 years) were randomly selected and assigned to 1 of the 3 groups: intrasession concurrent aerobic before (GAS: $n=39$ ) or after strength training (GSA: $n=$ 45 ) or control group (GC: $n=44$; no training program). The GC maintained their baseline level performance, and training-induced differences were found in the experimental groups. Increases were found in the $1-\mathrm{kg}$ and $3-\mathrm{kg}$ medicine ball throws: GAS: $+3 \%,+5.5 \%, p \leq 0.05, p<0.001$; GSA: $+5.7 \%,+8.7 \%, p$ $<0.001$, respectively; in the counter movement jump height and standing long jump length: GAS: $+6.5 \%,+3.4 \%, p \leq 0.05$; GSA: $+7 \%,+4.5 \%, p<0.001$, respectively; in the 20 -m shuttle-run time: GAS: $+2.3 \%$; GSA: $+4.6 \%, p<0.001$; and, in the $\dot{V}_{2}$ max: GAS: $+7.3 \%, p<0.001$; GSA: $+3.8 \%, p<0.001$ from pretraining to post-training. All programs were effective, but GSA produced better results than GAS for muscle strength variables, and GAS produced better results than GSA for aerobic capacity variables. The present study explored an unknown issue and added useful information to the literature in this area. These training methods should be taken into consideration to optimize explosive
\end{abstract}

Address correspondence to: Mikel Izquierdo, mikel.izquierdo@gmail.com. 30(12)/3267-3277

Journal of Strength and Conditioning Research

(C) 2016 National Strength and Conditioning Association strength and cardiorespiratory fitness training in school-based programs and sports club programs.

KEY WoRDS youth, power, cardiorespiratory, muscular conditioning, sequence

\section{INTRODUCTION}

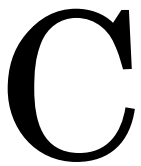
oncurrent training (i.e., a combination of strength and aerobic regimens) has become a recurrent topic for researchers because of the controversial results of different experiments $(6,8,10,16,23)$. Several studies have shown that concurrent training can affect the development of muscle strength and/or power $(16,20,24,29)$. In contrast, other experiments have indicated a positive effect of concurrent training on strength $(3,12,13,18,19,28)$ and on maximal aerobic capacity $(17,27,35,40)$.

Whereas multiple studies have investigated concurrent training in young, adult or even elderly populations $(9,12,22,33,42)$, a limited number of studies have explored concurrent training in prepubescent (33) and pubescent children (39). The majority of the pediatric research has focused on activities that enhance cardiorespiratory fitness and recent findings indicate that strength training offer benefits to children and adolescents $(15,26,39)$. Meanwhile, improvements in muscular fitness, speed and agility, rather than cardiorespiratory fitness, seem to have a positive effect on skeletal health $(26,39)$. Concurrent aerobic training and strength training have the potential to bring about gains in cardiorespiratory and muscular fitness simultaneously (25). Moreover, children and adolescents involved in physical education classes often perform strength and aerobic training concurrently in an effort to achieve specific adaptations to both forms of training $(24,39)$. Furthermore, Marta et al. (33) showed that concurrent training is equally effective on training-induced explosive strength as only strength training in prepubescent children. Moreover, this experiment only 
compared the effects of concurrent training on the same day vs. strength training alone. In fact, concurrent training order in prepubescent children is another important issue that still has not been investigated. According to Kang and Ratamess (25), most studies suggest that different intrasession training order produces no significant differences in training-induced adaptations because both combinations generate similar improvements in cardiorespiratory and muscular fitness. Furthermore, those studies also found that either training order can have its own advantages that could make concurrent training more effective. For example, Chtara et al. (9) observed that performing aerobic training before strength training could improve running performance and $\mathrm{V}_{2}$ max to a greater extent than the reverse order. Nevertheless, $\mathrm{Ca}$ dore et al. $(6,7)$ suggested that for intrasession concurrent training protocols, the strength gains might be optimized with intrasession strength before aerobic training order. To the best of our knowledge, no research has been conducted concerning the effects of intrasession concurrent strength and aerobic training order on training-induced explosive strength in prepubescent populations; thus, research in this area seems useful and relevant.

Therefore, the purpose of the current study was to analyze the interference of intrasession concurrent strength and aerobic training order over an 8-week period on explosive skills and maximal oxygen uptake ( $\mathrm{V}_{2}$ max) in a large sample of prepubescent children. We hypothesized that the prepubescent children would show increased explosive strength following the 8-week intrasession concurrent strength before aerobic training order, and that the prepubescent children would show increases $\mathrm{V}_{2}$ max independent of the training approach.

\section{Methods}

\section{Experimental Approach to the Problem}

The aim of the current study was to analyze the interference of intrasession concurrent strength and aerobic training order (strength before aerobic training [GSA] or aerobic before strength training [GAS]) over an 8-week period on explosive strength and maximal oxygen uptake ( $\left.{ }^{\mathrm{V}} \mathrm{O}_{2} \mathrm{max}\right)$ in prepubescent children. The study followed a repeated measures design, with each participant randomly assigned to a specific training program (concurrent strength and aerobic training or concurrent aerobic and strength training) or the control group (no training regimen). The 8-week period and study design were developed based on specific studies conducted in prepubescent children, which performed in similar periods $(32,33)$. Based on those studies, and the knowledge of an experienced coach and researcher, a training program composed of specific sets, repetitions, and exercises was designed. The children were evaluated for changes in strength (1-kg and $3-\mathrm{kg}$ medicine ball throw, standing long jump, counter movement jump, and a $20-\mathrm{m}$ sprint running) and cardiovascular parameters ( $\left.\mathrm{V}_{2} \mathrm{max}\right)$ before and after 8 weeks of training.

\section{Subjects}

The sample consisted of 128 healthy prepubescent children (aged $10.91 \pm 0.51$ years) from the Santa Clara school cluster (Guarda, Portugal) who were randomly assigned to the different training programs or the control group. The average height and body mass of the entire sample were $1.43 \pm$ $7.53 \mathrm{~m}$ and $39.12 \pm 8.60 \mathrm{~kg}$, respectively. The inclusion criteria were children aged 10-12 years (in fifth or sixth grade) without a chronic pediatric disease or orthopedic limitation and without regular extracurricular physical activity (i.e., practice of a sport at an academy).

Before data collection and the beginning of training, each participant reported any health problems, physical limitations, physical activity habits, and training experiences within the last 6 months. Thereafter, maturity level was determined based on Tanner stage (14) through selfassessment; to minimize the effects of growth, only children that were self-assessed as Tanner stage I-II were selected. No subject had regularly participated in any training program before this experiment. Efforts were made to collect participants that would form comparable groups. Before the start of the study, all participants and their parents/guardians were informed about study procedures and possible benefits and risks. The written informed consent was obtained from parents/guardians of all participants. The study was approved by the Institutional Review Board of the University of Beira Interior, and procedures were in accordance with the latest version of the Declaration of Helsinki. There were no injuries resulting from the implementation of the training programs.

\section{Procedures}

Sample Procedures. Children were recruited from a Portuguese public high school and randomly assigned to 2 experimental groups (8-week training, twice a week, from January 14 to March 15, 2015) and 1 control group. The groups were intrasession concurrent strength before aerobic training group (GSA: $n=45,24$ girls, 21 boys), intrasession concurrent aerobic before strength training group (GAS: $n=39,16$ girls, 23 boys), and a control group (GC: $n=44,23$ girls, 21 boys) with no training protocol. This last group followed the physical education class curriculum and did not undergo a specific training program. The assigned groups were determined randomly using a random number generator on a computer and could not be predicted. This procedure was established according to the "CONSORT" statement, which can be found at http://www.consort-statement. org/. The participants were randomly assigned to 1 of 3 intervention arms. Randomization was performed using $\mathrm{R}$ software version 2.14 (R Foundation for Statistical Computing and developed by Bell Laboratories, Lucent Technologies, Vienna, Austria). Before the start of training, all subjects attended physical education classes twice a week, with one class lasting 45 minutes and the other lasting $90 \mathrm{mi}^{-}$ nutes. Typical physical education classes have low-to- 
moderate intensity and involve the performance of various sports (team sports, gymnastics, dance, adventure sports, etc. ) with an evident pedagogical focus.

Training Procedures. The training programs were implemented in addition to the physical education classes. Before training, the subjects warmed up for approximately 10 minutes with low-to-moderate intensity exercises (e.g., running, sprints, stretching, and joint specific warm-up). Joint rotations, slow circular movements in the clockwise and counter-clockwise direction, were performed until the entire joint moved smoothly. Stretching exercises, including back and chest stretches, shoulder and side stretches, and wrist, waist, quadriceps, groin, and hamstring stretches, were performed. At the end of the training sessions, all subjects performed 5 minutes of static stretching exercises, such as kneeling lunges, the ankle-over-knee stretch, rotation, and hamstring stretches. After the warm-up period, the GSA group performed strength training and then a $20-\mathrm{m}$ shuttle- run exercise, whereas the GAS group performed a $20-\mathrm{m}$ shuttle-run exercise and then strength training. The aerobic training task was based on individual training volume that was set to approximately $75 \%$ of the established maximum aerobic volume achieved on a previous test. After 4 weeks of training, both experimental groups were reassessed by a $20-\mathrm{m}$ shuttle-run test to readjust the volume and intensity of the 20-m shuttle-run exercise.

Before the start of training, subjects completed 2 familiarization sessions to practice the exercises and routines that they would perform during the training period (i.e., power training exercises and $20-\mathrm{m}$ shuttle-run test). During this time, the children were taught the proper technique for each training exercise, and all of their questions were properly answered to remove any doubts regarding the exercise techniques. During training, the safety of the children, including the maintenance of safe hydration levels, was ensured, and all children were encouraged to do their best to achieve the best results. Clear instructions about the

TABLE 1. Training program design (sets $\times$ repetitions/distances).*

\begin{tabular}{|c|c|c|c|c|c|c|}
\hline \multicolumn{7}{|c|}{ Sessions } \\
\hline Exercise & 1 & 2 & 3 & 4 & 5 & 6 \\
\hline $\begin{array}{l}1-\mathrm{kg} \text { ball throw } \\
3-\mathrm{kg} \text { ball throw } \\
\text { SL jump } \\
\mathrm{CM} \text { jump } \\
20-\mathrm{m} \text { sprint }(\mathrm{m}) \\
20-\mathrm{m} \text { shuttle run (MAV, \%) }\end{array}$ & $\begin{array}{l}2 \times 8 \\
2 \times 8 \\
2 \times 4 \\
1 \times 5 \\
2 \times 20 \\
70\end{array}$ & $\begin{array}{l}2 \times 8 \\
2 \times 8 \\
2 \times 4 \\
1 \times 5 \\
2 \times 20 \\
70\end{array}$ & $\begin{array}{l}2 \times 8 \\
2 \times 8 \\
2 \times 4 \\
1 \times 5 \\
2 \times 20 \\
70\end{array}$ & $\begin{array}{l}2 \times 8 \\
2 \times 8 \\
2 \times 4 \\
1 \times 5 \\
2 \times 20 \\
70\end{array}$ & $\begin{array}{l}2 \times 8 \\
2 \times 8 \\
2 \times 4 \\
2 \times 5 \\
3 \times 20 \\
\quad 75\end{array}$ & $\begin{array}{l}2 \times 8 \\
2 \times 8 \\
2 \times 4 \\
2 \times 5 \\
3 \times 20 \\
\quad 75\end{array}$ \\
\hline \multicolumn{7}{|c|}{ Sessions } \\
\hline Exercise & 7 & 8 & 9 & 10 & 11 & 12 \\
\hline $\begin{array}{l}1-\mathrm{kg} \text { ball throw } \\
3-\mathrm{kg} \text { ball throw } \\
\text { SL jump } \\
\mathrm{CM} \text { jump } \\
20-\mathrm{m} \text { sprint }(\mathrm{m}) \\
20-\mathrm{m} \text { shuttle run (MAV, \%) }\end{array}$ & $\begin{array}{l}2 \times 8 \\
2 \times 8 \\
2 \times 4 \\
2 \times 5 \\
3 \times 20 \\
\quad 75\end{array}$ & $\begin{array}{l}2 \times 8 \\
2 \times 8 \\
2 \times 4 \\
2 \times 5 \\
3 \times 20 \\
\quad 75\end{array}$ & $\begin{array}{l}3 \times 8 \\
2 \times 8 \\
3 \times 4 \\
2 \times 5 \\
3 \times 20 \\
\quad 75\end{array}$ & $\begin{array}{l}3 \times 8 \\
2 \times 8 \\
3 \times 4 \\
2 \times 5 \\
3 \times 20 \\
\quad 75\end{array}$ & $\begin{array}{l}3 \times 8 \\
3 \times 6 \\
3 \times 4 \\
3 \times 5 \\
3 \times 30 \\
80\end{array}$ & $\begin{array}{c}3 \times 8 \\
3 \times 6 \\
3 \times 4 \\
3 \times 5 \\
3 \times 30 \\
\quad 80\end{array}$ \\
\hline \multicolumn{7}{|c|}{ Sessions } \\
\hline Exercise & \multicolumn{2}{|c|}{13} & 14 & \multicolumn{2}{|c|}{15} & 16 \\
\hline $\begin{array}{l}1-\mathrm{kg} \text { ball throw } \\
3-\mathrm{kg} \text { ball throw } \\
\text { SL jump } \\
\text { CM jump } \\
20-\mathrm{m} \text { sprint (m) } \\
20-\mathrm{m} \text { shuttle run (MAV, \%) }\end{array}$ & & 0 & $\begin{array}{l}3 \times 8 \\
3 \times 6 \\
4 \times 4 \\
3 \times 5 \\
3 \times 30 \\
80\end{array}$ & & & $\begin{array}{l}3 \times 8 \\
3 \times 6 \\
4 \times 4 \\
3 \times 5 \\
3 \times 30 \\
\quad 80\end{array}$ \\
\hline
\end{tabular}

*1-kg Ball Throw = chest $1-\mathrm{kg}$ medicine ball throwing $(\mathrm{m}) ; 3-\mathrm{kg}$ Ball Throw $=$ chest $3-\mathrm{kg}$ medicine ball throwing $(\mathrm{m}) ; \mathrm{SL} J u m p=$ standing long jump (m); CM Jump = counter movement jump onto a box $(\mathrm{m}) ; 20-\mathrm{m}$ Sprint $=20-\mathrm{m}$ sprint running $(\mathrm{s}) ; \mathrm{MAV}=$ maximal individual aerobic volume. 
importance of adequate nutrition were also delivered. The instructions for the $20-\mathrm{m}$ shuttle run were given with the aid of a multistage fitness test audio CD of the FITNESSGRAM test battery. During this time, all children were taught the proper technique for each training exercise, and all of their questions were properly answered to remove any doubts regarding the exercise techniques. Throughout the preexperimental and experimental periods, the subjects reported that they were not involved in regular exercise programs for developing or maintaining strength and endurance performance other than institutional regular physical education classes. A more detailed analysis of the program can be found in Table 1 .

The experimental groups were assessed for upper and lower body explosive strength (ball throws $1-3 \mathrm{~kg}$ and jumps, respectively), running speed $(20 \mathrm{~m}$ sprint), and $\mathrm{V}{ }_{2}$ max (20-m shuttle-run test) before and after the 8 weeks of the training program. The testing assessment procedures were always conducted in the same indoor environment and at the same time each week. Each subject was familiarized with the power training tests (ball throws, jumps, and sprints) and with the 20-m multistage shuttle-run test. The same researcher performed the training program, anthropometric and physical fitness assessments, and data collection.

\section{Testing Procedures. Anthropometric Measurements.} All anthropometric measurements were assessed according to international standards for anthropometric assessment (31) and were obtained before any physical performance test. The participants were barefoot and only wearing underwear. Body mass (in $\mathrm{kg}$ ) was measured to the nearest $0.1 \mathrm{~kg}$ using a standard digital floor scale (model 841; Seca, Hamburg,
Germany). A precision stadiometer with a scale range of $0.001 \mathrm{~m}$ was used to measure body height (in $\mathrm{m}$ ) (Seca).

Medicine Ball Throwing. This test was performed according to the protocol described by Mayhew et al. (34). The subjects were seated with the backside of their trunk touching a wall. They were required to hold medicine balls (Bhalla International, Vinex Sports, Meerut, India) that weighed $1 \mathrm{~kg}$ (Vinex; model, VMB-001R; perimeter, $0.72 \mathrm{~m}$ ) and $3 \mathrm{~kg}$ (Vinex; model, VMB-003R; perimeter, $0.78 \mathrm{~m}$ ) with their hands (abreast of chest) and throw the ball forward for the maximum possible distance. Neither hip inflection nor withdrawal of the trunk away from the wall was allowed. Three trials were performed. The throws were measured (in $\mathrm{m}$ ) from the wall to the first point at which the ball made contact with the floor, and the furthest throw was recorded. One minute of rest was provided between the 3 trials. The intraclass correlation coefficients (ICCs) for the data of the $1-\mathrm{kg}$ and $3-\mathrm{kg}$ medicine ball throwing exercises were both $\approx 0.98$.

Standing Long Jump (SL Jump). This test was assessed using the EUROFIT test battery (1). The participants stood with their feet slightly apart (toes behind a starting line) and jumped as far forward as possible. Three trials were performed. The distance jumped was measured (in $\mathrm{m}$ ) from the starting line to the heel of the foot nearest the starting line, and the furthest distance was recorded. The ICCs for the standing long jump data were 0.94 .

Counter Movement Vertical Jump (CM Jump). This test was conducted on a contact mat connected to an electronic power timer, control box, and handset (Globus Ergojump, Italy). From a standing position, with their feet

TABLE 2. Univariate analysis. ${ }^{*} \dagger$

\begin{tabular}{lrrrl}
\hline & GSA & GAS & GC & $p$ \\
\hline Age (mean $+S D)$ & $10.8 \pm 0.5$ & $11.1 \pm 0.5$ & $10.9 \pm 0.5$ & $0.038 \ddagger$ \\
BMI (mean $+S D)$ & $19.3 \pm 3.0$ & $18.2 \pm 3.1$ & $19.2 \pm 3.1$ & 0.346 \\
FAT (mean $+S D)$ & $22.6 \pm 8.3$ & $18.6 \pm 8.8$ & $21.6 \pm 7.0$ & 0.290 \\
VA ${ }_{2}$ max $\left(\mathrm{ml} \cdot \mathrm{kg}^{-1} \cdot \mathrm{min}^{-1}\right)$ & $44.4 \pm 3.3$ & $42.5 \pm 3.1$ & $44.8 \pm 3.6$ & $0.000 \S$ \\
$1-\mathrm{kg}$ ball throw $(\mathrm{m})$ & $3.6 \pm 0.6$ & $3.3 \pm 0.7$ & $3.6 \pm 0.6$ & $0.000 \S$ \\
3-kg ball throw (m) & $2.2 \pm 0.4$ & $2.3 \pm 0.4$ & $2.2 \pm 0.4$ & 0.081 \\
SL jump (m) & $1.3 \pm 0.2$ & $1.3 \pm 0.3$ & $1.3 \pm 0.2$ & 0.659 \\
CM jump (m) & $0.2 \pm 0.0$ & $0.2 \pm 0.1$ & $0.2 \pm 0.1$ & 0.442 \\
20-m sprint (s) & $4.4 \pm 0.3$ & $4.3 \pm 0.3$ & $4.4 \pm 0.3$ & $0.013 \ddagger$ \\
\hline
\end{tabular}

${ }^{*} \mathrm{~V}_{2} \max =$ multistage shuttle run $\left(\mathrm{ml} \cdot \mathrm{kg}^{-1} \cdot \mathrm{min}^{-1}\right) ; 1-\mathrm{kg}$ Ball Throw $=$ chest $1-\mathrm{kg}$ medicine ball throwing $(\mathrm{m}) ; 3-\mathrm{kg}$ Ball Throw $=$ chest 3-kg medicine ball throwing $(\mathrm{m}) ; \mathrm{SL}$ Jump = standing long jump (m); CM Jump = counter movement jump onto a box $(\mathrm{m}) ; 20-\mathrm{m}$ Sprint $=20-\mathrm{m}$ sprint running (s).

$\dagger$ Mean $\pm S D$ of age, body mass index (BMI), \% fat mass (FAT), maximal oxygen uptake $\left(\mathrm{V}_{2}\right.$ max), and muscle strength variables in intrasession strength before aerobic training (GSA), intrasession aerobic before strength training (GAS), and control group (GC). $\ddagger p \leq 0.05$. $\S p<0.001$. 
shoulder-width apart and hands placed on the pelvic girth, the subjects performed a counter movement with their legs before jumping. Such movement makes use of the stretch-shorten cycle in which the muscles are prestretched before shortening in the desired direction (30). The subjects were informed that they should try to jump vertically as high as possible. Each participant performed 3 jumps with a 1-minute recovery between attempts. The highest jump (in $\mathrm{m}$ ) was recorded. The ICCs of the counter movement vertical jump data were 0.91 .

20-Meter Sprint Running (20 m Sprint Running). The subjects were required to cover a $20-\mathrm{m}$ distance on a track in the shortest time possible. The time (in s) to run $20 \mathrm{~m}$ was obtained using photocells (Brower Timing System, Fairlee, VT, USA). Three trials were performed, and the best time (seconds and hundredths) was recorded. The ICCs of the sprint running data were 0.97 .

\section{Statistical Analyses}

Standard statistical methods were used to calculate means and standard deviations. The normality of the data distribution was evaluated by applying the Kolmogorov-Smirnov test. The within-subject reliabilities of the endurance and strength tests were determined by calculating ICCs and 95\% confidence intervals (CIs). We performed univariate analyses (one-way ANOVA and Qui-Squared test) to compare physical performance variables, age, BMI, and body fat at baseline between the groups. To evaluate the changes from pretreatment to post-treatment, we used a paired $t$-test for each group, and we performed a multivariate analysis of covariance (MANCOVA) with group as fixed-effect and physical performances variables as covariates. The normality of the residuals was examined by the Kolmogorov-Smirnov test, and the homogeneity of the variance-covariance matrix was examined by the Box's $M$ test. This assumption was not verified, so we used Pillai's trace test statistics $(M=81.70$, $\left.F_{(2,125)}=1.81, p \leq 0.05\right)$. When statistically significant differences were observed between groups, an analysis of covariance (ANCOVA) was performed for each dependent variable, followed by the Bonferroni post hoc comparison test. Using the ANCOVA results, it was also possible to analyze the effect size of the intervention on the physical performance variables. The data were analyzed using SPSS 22.0 (International Business Machines Corporation-IBM, Armonk, NY, USA), and statistical significance was set at $p \leq 0.05$.

TABLE 3. Mean $\pm S D$ and paired $t$-test analysis. ${ }^{*} \dagger$

\begin{tabular}{|c|c|c|c|c|}
\hline & Pre & Post & Difference (Pre - post) & $p$ \\
\hline \multicolumn{5}{|l|}{ GAS } \\
\hline$\dot{\mathrm{V}}_{2} \max \left(\mathrm{ml} \cdot \mathrm{kg}^{-1} \cdot \mathrm{min}^{-1}\right)$ & $42.5 \pm 3.1$ & $45.6 \pm 3.2$ & $-3.1 \pm 1.7$ & $0.000 \ddagger$ \\
\hline 1-kg ball throw $(\mathrm{m})$ & $3.3 \pm 0.7$ & $3.4 \pm 0.7$ & $-0.1 \pm 0.2$ & $0.033 \S$ \\
\hline 3-kg ball throw (m) & $2.3 \pm 0.4$ & $2.4 \pm 0.5$ & $-0.1 \pm 0.1$ & $0.000 \ddagger$ \\
\hline SL jump (m) & $1.3 \pm 0.3$ & $1.4 \pm 0.3$ & $-0.1 \pm 0.2$ & $0.025 \S$ \\
\hline CM jump (m) & $0.2 \pm 0.1$ & $0.2 \pm 0.1$ & $0.0 \pm 0.0$ & $0.001 \S$ \\
\hline 20-m sprint (s) & $4.3 \pm 0.3$ & $4.2 \pm 0.3$ & $-0.1 \pm 0.0$ & $0.000 \ddagger$ \\
\hline \multicolumn{5}{|l|}{ GSA } \\
\hline$\dot{\mathrm{V}}_{2} \max \left(\mathrm{ml} \cdot \mathrm{kg}^{-1} \cdot \mathrm{min}^{-1}\right)$ & $44.4 \pm 3.3$ & $46.1 \pm 4.1$ & $-1.7 \pm 1.9$ & $0.000 \ddagger$ \\
\hline $1-\mathrm{kg}$ ball throw $(\mathrm{m})$ & $3.6 \pm 0.6$ & $3.8 \pm 0.6$ & $-0.2 \pm 0.1$ & $0.000 \ddagger$ \\
\hline 3-kg ball throw (m) & $2.2 \pm 0.4$ & $2.4 \pm 0.4$ & $-0.2 \pm 0.1$ & $0.000 \ddagger$ \\
\hline SL jump (m) & $1.3 \pm 0.2$ & $1.4 \pm 0.2$ & $-0.1 \pm 0.1$ & $0.000 \ddagger$ \\
\hline $\mathrm{CM}$ jump (m) & $0.2 \pm 0.0$ & $0.2 \pm 0.0$ & $0.0 \pm 0.2$ & $0.000 \ddagger$ \\
\hline 20-m sprint (s) & $4.4 \pm 0.3$ & $4.3 \pm 0.3$ & $-0.1 \pm 0.1$ & $0.000 \ddagger$ \\
\hline \multicolumn{5}{|l|}{ GC } \\
\hline$\dot{\mathrm{V}}_{2} \max \left(\mathrm{ml} \cdot \mathrm{kg}^{-1} \cdot \mathrm{min}^{-1}\right)$ & $44.8 \pm 3.6$ & $45.0 \pm 4.0$ & $-0.2 \pm 1.6$ & 0.386 \\
\hline $1-\mathrm{kg}$ ball throw $(\mathrm{m})$ & $3.6 \pm 0.6$ & $3.7 \pm 0.6$ & $-0.1 \pm 0.1$ & 0.053 \\
\hline 3-kg ball throw (m) & $2.2 \pm 0.4$ & $2.2 \pm 0.5$ & $-0.1 \pm 0.2$ & 0.057 \\
\hline SL jump (m) & $1.3 \pm 0.2$ & $1.3 \pm 0.2$ & $-0.1 \pm 0.1$ & 0.066 \\
\hline CM jump (m) & $0.2 \pm 0.1$ & $0.2 \pm 0.1$ & $0.0 \pm 0.2$ & 0.103 \\
\hline 20-m sprint (s) & $4.4 \pm 0.3$ & $4.4 \pm 0.3$ & $0.0 \pm 0.1$ & 0.076 \\
\hline
\end{tabular}

${ }^{*} \mathrm{~V}_{2} \max =$ multistage shuttle run $\left(\mathrm{ml} \cdot \mathrm{kg}^{-1} \cdot \mathrm{min}^{-1}\right) ; 1-\mathrm{kg}$ Ball Throw $=$ chest $1-\mathrm{kg}$ medicine ball throwing $(\mathrm{m}) ; 3-\mathrm{kg}$ Ball Throw $=$ chest 3-kg medicine ball throwing (m); SL Jump = standing long jump (m); CM Jump = counter movement jump onto a box (m); 20-m Sprint $=20-\mathrm{m}$ sprint running (s).

$\dagger$ Mean $\pm S D$ and paired t-test to maximal oxygen uptake $\left(\mathrm{V}_{2} \max \right)$ and muscle strength variables pretraining and post-training in intrasession strength before aerobic training (GSA), intrasession aerobic before strength training (GAS) and control group (GC). $\ddagger p<0.001$. $\S p \leq 0.05$. 


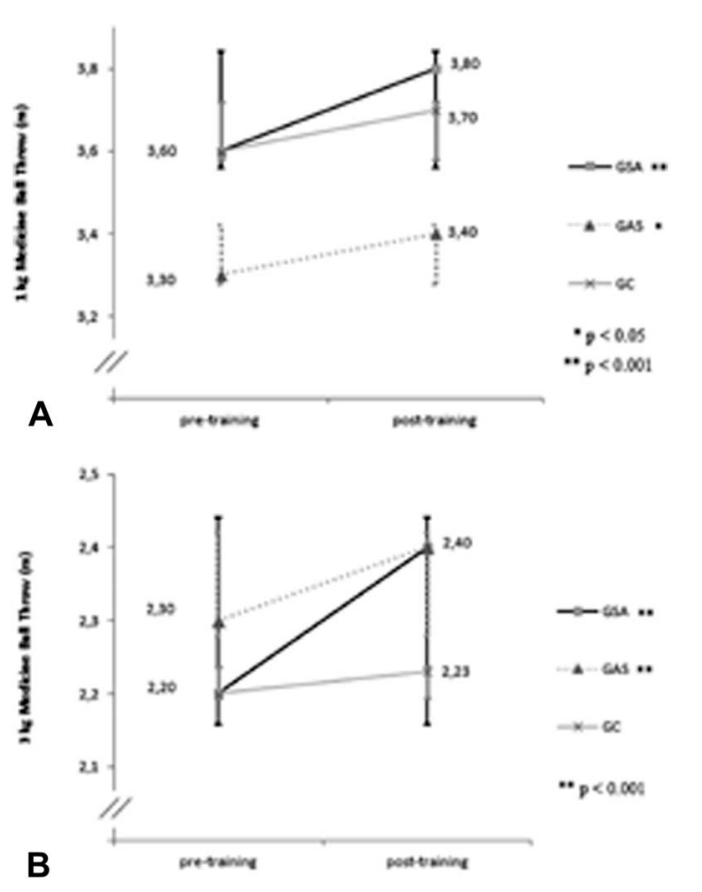

Figure 1. A) Obtained values in pretest and post-test of training in intrasession strength before aerobic training (GSA), intrasession aerobic before strength training (GAS), and control group (GC) on 1-kg medicine ball throw, (B) obtained values in pretest and post-test of training in intrasession strength before aerobic training (GSA), intrasession aerobic before strength training (GAS), and control group (GC) on 3-kg medicine ball throw.

\section{Results}

In pretraining, the results showed no differences in BMI, body fat, or any explosive strength variables between groups, with the exception of age $\left(F_{(2,125)}=3.36, p \leq 0.05\right)$ and aerobic capacity $\left(\dot{\mathrm{V}}_{2} \mathrm{max}\right)\left(F_{(2,125)}=5.44, p \leq 0.05\right)$. We also showed differences between the GSA and GAS groups, and between the GAS, GSA, and GC groups (Table 2).

The explosive strength variables and the aerobic capacity variable increased significantly in the GSA and GAS groups from before to after the 8-week training session. The GC group presented no significant increases in the explosive strength variables nor in the aerobic capacity variable (Table 3). These results did not support the hypothesis that $\mathrm{VO}_{2}$ max increases independently from the implemented exercise training programs.

Regarding the effects of different types of training on explosive strength, changes from pretraining to post-training were observed (Table 3). The GSA group showed better improvement in the $1-\mathrm{kg}$ medicine ball throw, $3-\mathrm{kg}$ ball medicine ball throw, SL jump, CM jump, and 20-m sprint running tests compared with the other experimental group. The GAS group showed better improvement in $\mathrm{V}_{2}$ max than GSA group.

There was a small effect of the group factor on changes in explosive strength measures from pretraining to posttraining $\left(\eta_{\mathrm{p}}^{2}=0.37, p<0.001\right)$. Moreover, medium effect sizes of the group factor were found for $\dot{\mathrm{V}}_{2} \max \left(\eta_{\mathrm{p}}^{2}=0.27\right.$, $\left.F_{(2,125)}=22.10, p<0.001\right)$ and $20-\mathrm{m}$ sprint running $\left(\eta_{\mathrm{p}}^{2}=\right.$ $\left.0.30, F_{(2,125)}=25.18, p<0.001\right)$. Small effect sizes of the group factor were found for the $1-\mathrm{kg}$ medicine ball throw

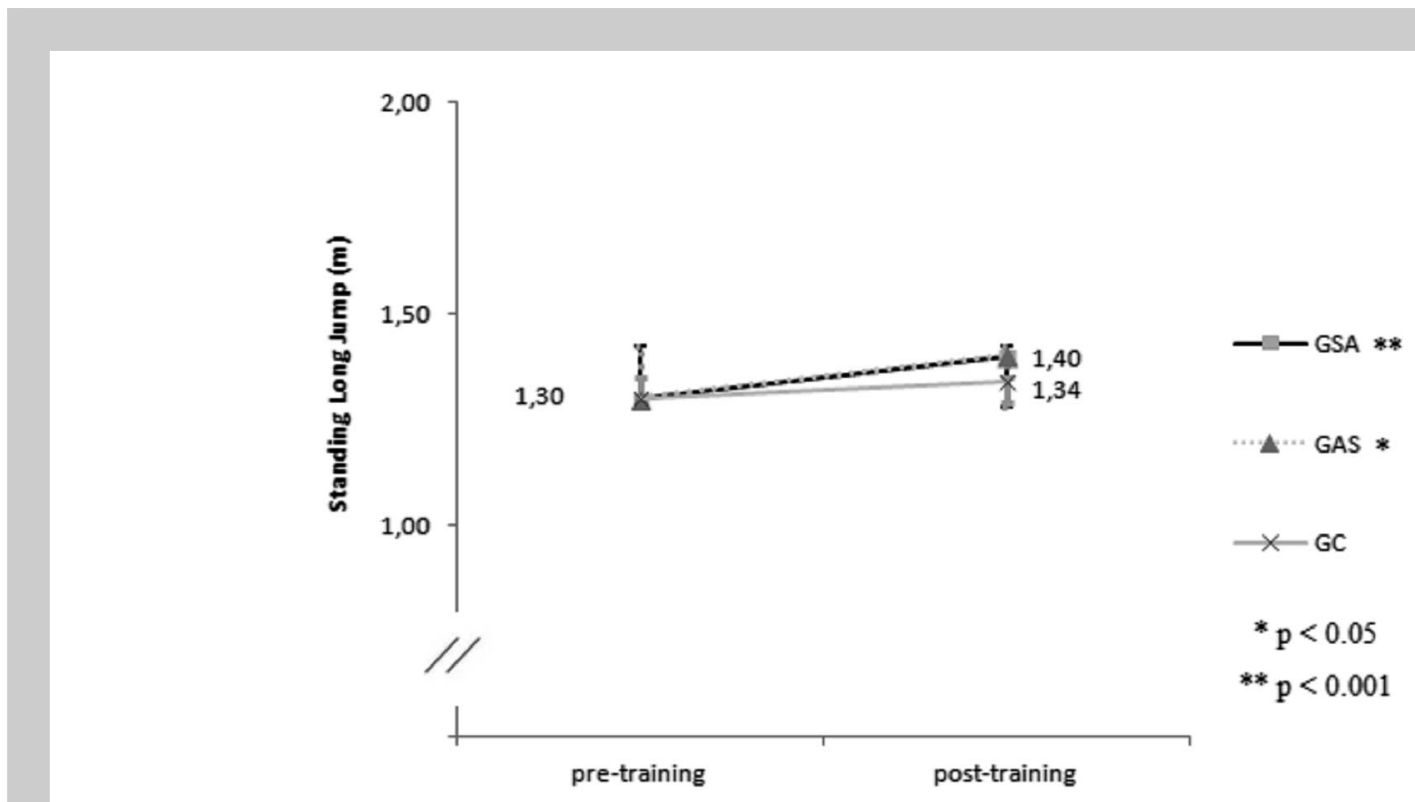

Figure 2. Obtained values in pretest and post-test of training in intrasession strength before aerobic training (GSA), intrasession aerobic before strength training (GAS), and control group (GC) on standing long jump. 


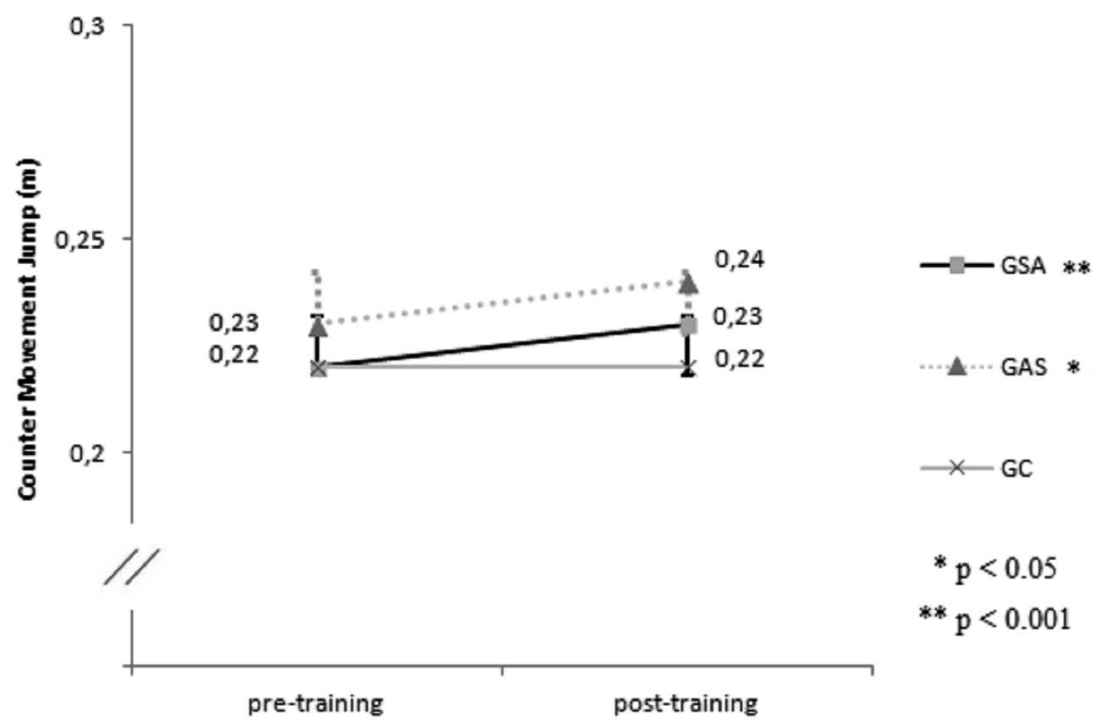

Figure 3. Obtained values in pretest and post-test of training in intrasession strength before aerobic training (GSA), intrasession aerobic before strength training (GAS), and control group (GC) on counter movement jump.

$\left(\eta_{\mathrm{p}}^{2}=0.17, F_{(2,125)}=12.40, p<0.001\right), 3-\mathrm{kg}$ medicine ball throw $\left(\eta_{\mathrm{p}}^{2}=0.16, F_{(2,125)}=11.60, p<0.001\right)$, and SL jump $\left(\eta_{\mathrm{p}}^{2}=0.05, F_{(2,125)}=3.37, p \leq 0.05\right)$. A small effect size was also found for the CM jump $\left(\eta_{\mathrm{p}}^{2}=0.04, F_{(2,125)}=2.22, p=\right.$ 0.11 ), but the differences in the CM jump results between groups were not statistically significant.
We presented changes in the $3-\mathrm{kg}$ medicine ball throw (Figure 1B), SL jump (Figure 2), and CM jump (Figure 3). Results from before to after training were significantly higher in the GSA and GAS groups than in the GC group. The increases in the 1-kg medicine ball throw (Figure 1A) and 20-m sprint running (Figure 4) results were significantly

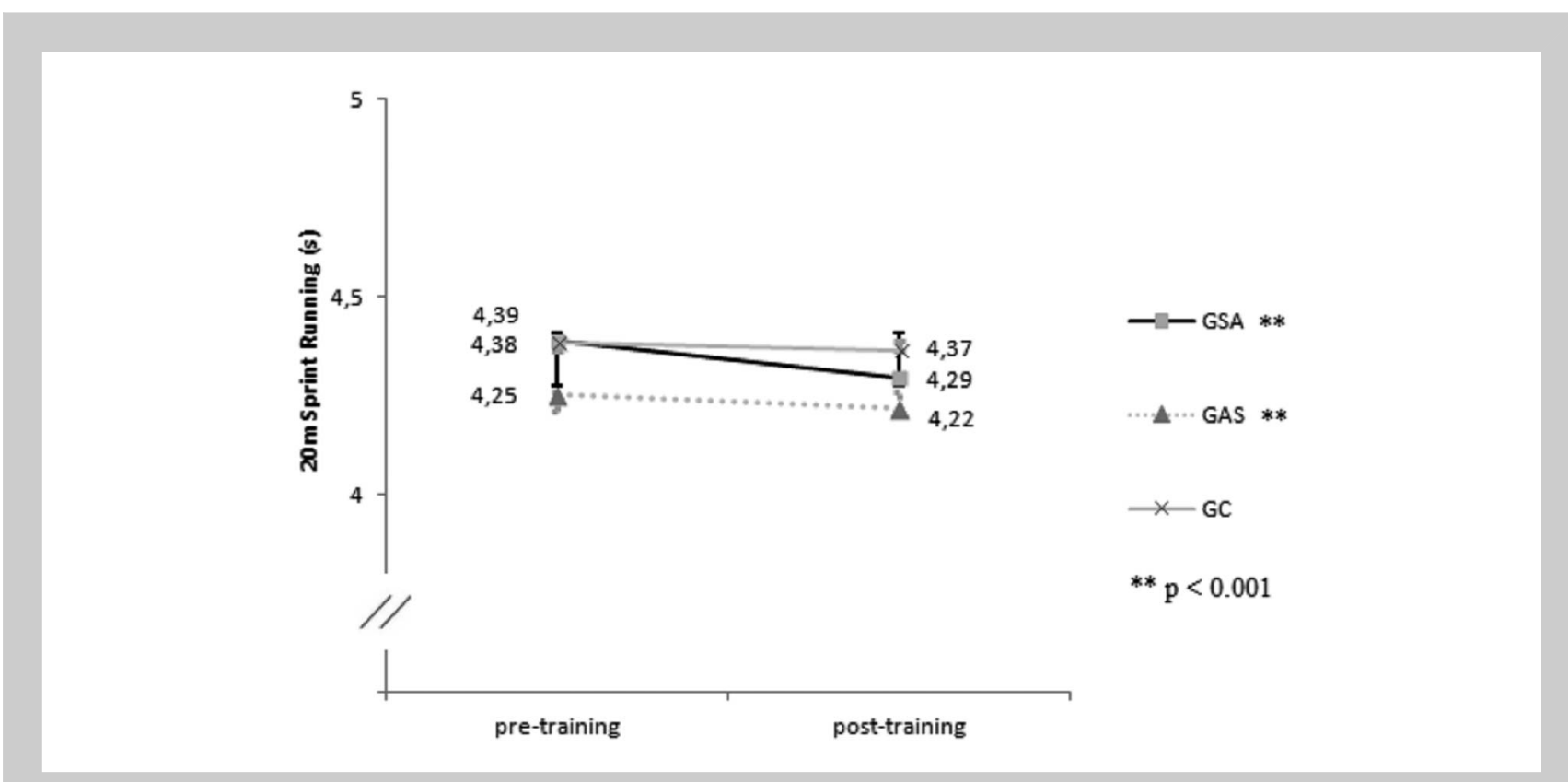

Figure 4. Obtained values in pretest and post-test of training in intrasession strength before aerobic training (GSA), intrasession aerobic before strength training (GAS), and control group (GC) on 20-m sprint running. 


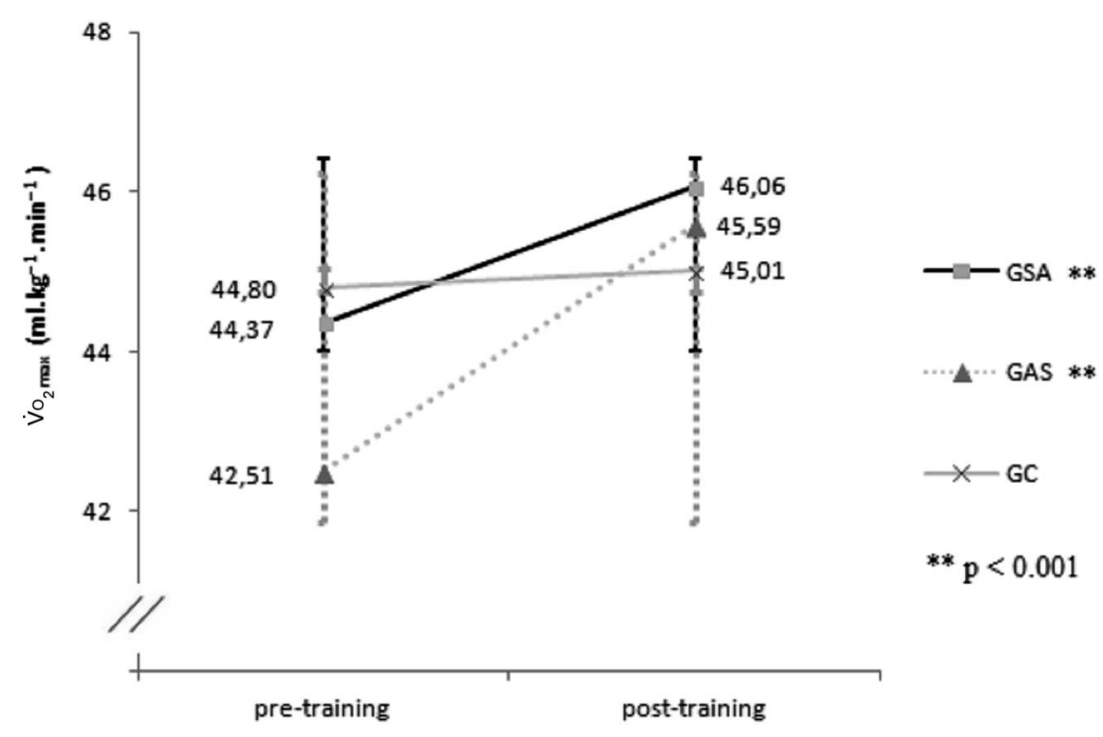

Figure 5. Obtained values in pretest and post-test of training in intrasession strength before aerobic training (GSA), intrasession aerobic before strength training (GAS), and control group (GC) on maximal oxygen uptake $\left(\dot{\mathrm{V}}_{2} \mathrm{max}\right)$.

higher in the GSA group than in the GAS group. In addition, $\dot{\mathrm{V}}_{2} \max$ (Figure 5) increased more in the GAS group than in the GSA group.

\section{Discussion}

The present study is the first to investigate the order effect of concurrent strength and aerobic training among prepubescent children. Specifically, the purpose of the current study was to compare the effects of an 8-week period of concurrent strength and aerobic training order on explosive skills and $\dot{\mathrm{V}}_{2} \max$ training parameters in prepubescent children. The main findings indicated that the intrasession concurrent training order (strength before aerobic training/aerobic before strength training) programs investigated here were effective, well-rounded exercise programs that can be performed to improve explosive strength in prepubescent children. Nevertheless, the GSA group produced better results than the GAS group. Additionally, the GAS group showed greater improvement in cardiorespiratory fitness than the other experimental group. These results are of great interest and are useful for optimizing and innovating schoolbased programs at sports clubs for children.

Concurrent strength and aerobic training have the potential to improve cardiorespiratory and muscular fitness simultaneously $(6,8,40)$. However, for concurrent training, the best order for aerobic and strength intrasession training is unclear. For example, there are studies $(4,11)$ that have reported that intrasession strength and aerobic training, regardless of training order, can similarly improve aerobic capacity and muscular strength and conclude that both training orders are equally effective. Yet, in the recent study, Kang and Ratamess (25) found that each intrasession training order had its own advantages that should be considered to make concurrent training more effective. Although the order effect of intrasession concurrent strength and aerobic training on training-induced explosive strength in prepubescent children has not yet been explored, the present study may provide reliable and useful information in this area.

In the current study, no significant differences were found between experimental groups (GSA and GAS) after training on the variables related to explosive strength and aerobic capacity, with the exception of the $1-\mathrm{kg}$ medicine ball throw $(p \leq 0.05)$. Moreover, there were overall increases in explosive strength of the upper and lower limbs for both experimental training groups, suggesting that intrasession strength training before aerobic training and intrasession aerobic training before strength training are both beneficial training stimuli for enhancing explosive strength and aerobic capacity in prepubescent children. The GSA group showed higher improvements than the GAS group in muscle strength variables: the medicine ball throws were higher $(2.7$ and $2.2 \%$ for the 1-kg and 3-kg medicine balls, respectively; $p \leq 0.05$ ), the jumps were higher $(1.1$ and $0.5 \%$ for the $\mathrm{CM}$ and SL jumps, respectively; $p \leq 0.05$ ), the 20 -m times were lower $(2.3 \%, p<0.001)$. These results indicated that intrasession strength before aerobic training may be more effective than intrasession aerobic training before strength training to improve explosive strength in young children. This is 
consistent with studies by Cadore et al. $(6,7)$ that observed greater maximal dynamic strength gains (upper and lower body) and greater force per unit of muscle mass in elderly men from a concurrent training group that performed strength training before aerobic training (maximal dynamic strength of upper body: $+15 \%$, maximal dynamic strength of lower body: $+35.1 \%$, and force per unit of muscle mass: $+27.5 \%, p<0.001, p<0.01$, and $p<0.001$, respectively) compared with the reverse order (maximal dynamic strength of upper body: $+11.5 \%$, maximal dynamic of lower body: $+21.9 \%$, and force per unit of muscle mass: $+15.2 \%, p<$ $0.001, p<0.01$, and $p<0.02$, respectively).

Interestingly, the $\mathrm{V}_{2}$ max was significantly greater after training in the GAS group compared with the GSA group (GAS: $+7.3 \%$; GSA: $+3.8 \%, p<0.001$ ), suggesting that intrasession aerobic training before strength training may be more effective than intrasession strength training before aerobic training at improving aerobic capacity in prepubescent children. Nevertheless, this difference could have been because of the order of training used in the different groups or to acute neuromuscular fatigue induced by strength training (used in the GSA and GAS groups). Such residual fatigue may reduce the quality of aerobic training, leading to a reduction in aerobic development over time (38). In fact, the results of the present study are in line with the results of Chtara et al. (9), who investigated training order of concurrent aerobic and strength training on aerobic capacity and performance in male sports students (during 12 weeks, twice a week) and found that performing aerobic training before strength training could improve running performance and $\dot{\mathrm{V}}_{2}$ max to a greater extent than the reverse order $(+8.57$ and $+13.71 \%, p<0.01$ and $p<$ 0.01 vs. +4.66 and $+11.01 \%, p \leq 0.05$ and $p<0.01$, respectively).

There is no consensus on the interference of intrasession concurrent training order in performance adaptations. There are studies $(2,36,41)$ that have reported that intrasession strength and aerobic training, regardless of training order, does not impair physiological and performance adaptations. In contrast, other studies have provided evidence that the order of intrasession strength and aerobic training may affect performance adaptations $(4,9,21)$. However, our findings may clarify previous evidence. Thus, in the current study, improvements in the explosive strength and in the aerobic capacity for both experimental training groups were found, indicating that concurrent training, regardless of training order, does not affect performance in school-age children. This is consistent with recent work showing that concurrent training is equally effective on training-induced explosive strength as only strength training in prepubescent children (33).

In brief, our data suggested that training order influences muscle strength and aerobic capacity improvement in prepubescent children. Therefore, these results are meaningful for the development of explosive strength and cardiorespiratory fitness training in school-based programs and sports clubs' programs, improving the specificity of training related to children characteristics, and contributing for the achievement of the results proposed. Furthermore, intrasession concurrent training order (strength training before aerobic training or aerobic training before strength training) seems to be effective at improving both explosive strength and aerobic capacity. Although all programs were effective, the GSA group produced better improvement in muscle strength variables than the GAS group, and the GAS group produced better improvement in aerobic capacity variables than the GSA group. Thus, it is also suggested that the effectiveness of the intrasession strength and aerobic training order may be dependent on the programs' priorities. Nevertheless, there are some limitations of this study that should be addressed: (a) field tests were only applied in the experimental training groups, and laboratory tests with higher control standards may have generated more accurate data; (b) different methods of organizing training workouts can lead to different training-induced outcomes.

\section{Practical Applications}

To increase the efficiency of physical education classes and to optimize exercise programs, intrasession strength before aerobic training and intrasession aerobic before strength training programs should be considered in school-based and sports clubs' programs. Furthermore, the youth strength and conditioning programs should include explosive strength and aerobic training as these are related with improvements in health, fitness, academic performance, and quality of life $(5,37)$. However, if the main purpose is to improve aerobic capacity, intrasession aerobic before strength training should be used. To improve muscular strength, intrasession strength before aerobic training would be the most suitable alternative. Therefore, the current study is innovative, and these findings can be helpful for teachers, coaches, and researchers in their efforts with prepubescent children.

\section{ACKNowledgments}

The authors would like to thank all the children who participated in this research and also that of the Santa Clara Middle School in making available the context facilities. The authors have no professional relationships with any companies or manufacturers identified in this study. The authors have no conflict of interests that are directly relevant to the content of this study. The results of the present study do not constitute endorsement of the product by the authors or the NSCA. This work was supported by University of Beira Interior, by the National Funds through FCT, Portuguese Foundation for Science and Technology (UID/ DTP/04045/2013) and the European Fund for regional development (FEDER) allocated by European Union through the COMPETE2020Programme (POCI-01-0145-FEDER-006969), Competitiveness and internationalization (POCI). 


\section{REFERENCES}

1. Adam, C, Klissouras, V, Ravassolo, M, Renson, R, Tuxworth, W, Kemper, H, Vanmechelen, W, Hlobil, H, Beunen, G, LevarletJoye, H, and Vanlierde, A. Eurofit: Handbook for the Eurofit Test of Physical Fitness. Rome: Edigraf Editoriale Gráfica, 1988.

2. Ali-Mohamadi, M, Abbaspoor, M, Rahimi, R, and Hakimi, M. The influence of order execution components of the strength and endurance in the concurrent training on lipid profile and body composition in overweight females. World Appl Sci J 29: 946-953, 2014.

3. Baker, D. The effects of an in-season concurrent training on the maintenance of maximal strength and power in professional and college-aged rugby league football players. J Strength Cond Res 15: 172-177, 2001.

4. Bell, GJ, Petersen, SR, Quinney, HA, and Wenger, HA. Sequencing of endurance and high- velocity strength training. Can J Sport Sci 13: 214-219, 1988.

5. Brown, LE. Strength training. In: National Strength and Conditioning Association. L.E. Brown, eds. Colorado: Human Kinetics, 2007. pp. 319-332.

6. Cadore, EL, Izquierdo, M, Alberton, CL, Pinto, RS, Conceição, M, Cunha, G, Radaelli, R, Bottaro, M, Trindade, GT, and Kruel, LF. Strength prior to endurance intra-session exercise sequence optimizes neuromuscular and cardiovascular gains in elderly men. Exp Gerontol 47: 164-169, 2012.

7. Cadore, EL, Izquierdo, M, Pinto, SS, Alberton, CL, Pinto, RS, Baroni, BM, Vaz, MA, Lanferdini, FJ, Radaelli, R, González-Izal, M, Bottaro, M, and Kruel, LFM. Neuromuscular adaptations to concurrent training in the elderly: Effects of intrasession exercise sequence. Age 35: 891-903, 2012.

8. Cadore, EL, Pinto, RS, Bottaro, M, and Izquierdo, M. Strength and endurance training prescription in healthy and frail elderly. Aging Dis 5: 183-195, 2014.

9. Chtara, M, Chamari, K, Chaouachi, M, Chaouachi, A, Koubaa, D, Feki, Y, Millet, G, and Amri, M. Effects of intra-session concurrent endurance and strength training sequence on aerobic performance and capacity. Br J Sports Med 39: 555-560, 2005.

10. Chtara, M, Chaouachi, A, Levin, GT, Chaouachi, M, Chamari, K, Amri, M, and Laursen, PB. Effect of concurrent endurance and circuit resistance training sequence on muscular strength and power development. J Strength Cond Res 22: 1037-1045, 2008.

11. Collins, MA and Snow, TK. Are adaptations to combined endurance and strength training affected by the sequence of training?. J Sports Sci 11: 485-491, 1993.

12. Davis, WJ, Wood, DT, Andrews, RG, Elkind, LM, and Davis, WB. Concurrent training enhances athletes' cardiovascular and cardiorespiratory measures. J Strength Cond Res 22: 1503-1514, 2008.

13. Davis, WJ, Wood, DT, Andrews, RG, Elkind, LM, and Davis, WB. Concurrent training enhances athletes' strength, muscle endurance, and other measures. J Strength Cond Res 22: 1487-1502, 2008.

14. Duke, PM, Litt, IR, and Gross, RT. Adolescents self-assessment of sexual maturation. Pediatrics 66: 918-920, 1980.

15. Faigenbaum, $\mathrm{AD}$ and Myer, GD. Pediatric resistance training: Benefits, concerns, and program design considerations. Curr Sports Med Rep 9: 161-168, 2010.

16. García-Pallarés, J and Izquierdo, M. Strategies to optimize concurrent training of strength and aerobic fitness for rowing and canoeing. Sports Med 41: 329-343, 2011.

17. Glowacki, SP, Martin, SE, Maurer, A, Baek, W, Green, JS, and Crouse, SF. Effects of resistance, endurance, and concurrent exercise on training outcomes in men. Med Sci Sports Exerc 36: 2119-2127, 2004.

18. Gorostiaga, EM, Izquierdo, M, Iturralde, $P$, Ruesta, $M$, and Ibanez, J. Effects of heavy resistance training on maximal and explosive force production, endurance and serum hormones in adolescent handball players. Eur J Appl Physiol Occup Physiol 80: 485-493, 1999.
19. Gravelle, BL and Blessing, DL. Physiological adaptation in women concurrently training for strength and endurance. $J$ Strength Cond Res 14: 5-13, 2000.

20. Hennessy, LC and Watson, AWS. The interference effects of training for strength and endurance simultaneously. J Strength Cond Res 8: 12-19, 1994.

21. Hickson, RC. Interference of strength development by simultaneously training for strength and endurance. Eur J Appl Physiol Occup Physiol 45: 255-263, 1980.

22. Holviala, J, Häkkinen, A, Karavirta, L, Nyman, K, Izquierdo, M, Gorostiaga, EM, Avela, J, Korhonen, J, Knuutila, VP, Kraemer, WJ, and Häkkinen, K. Effects of combined strength and endurance training on treadmill load carrying walking performance in aging men. J Strength Cond Res 24: 1584-1595, 2010.

23. Izquierdo, M, Ibañez, J, Häkkinen, K, Kraemer, WJ, Larrión, JL, and Gorostiaga, EM. Once weekly combined resistance and cardiovascular training in healthy older men. Med Sci Sports Exerc 36: 435-443, 2004.

24. Izquierdo-Gabarren, M, Expósito, RGT, García-Pallarés, J, SanchesMedina, L, Villarreal, ESS, and Izquierdo, M. Concurrent endurance and strength training not to failure optimizes performance gains. Med Sci Sports Exerc 42: 1191-1199, 2010.

25. Kang, Y and Ratamess, N. Which comes first? resistance before aerobic exercise or vice versa?. ACSM 18: 9-14, 2014

26. Kemper, HCG, Twisk, JWR, Van Mechelen, W, Post, GB, Roos, JC, and Lips, P. Fifteen-year longitudinal study in young adults on the relation of physical activity and fitness with the development of the bone mass: The Amsterdam growth and health longitudinal. Study Bone 27: 847-853, 2000.

27. Kraemer, WJ, Keuning, M, Ratamess, NA, Volek, JS, McCormick, M, Bush, JA, Nindl, BC, Gordon, SE, Mazzetti, SA, Newton, RU, Gomez, AL, Wickham, RB, Rubin, MR, and Häkkinen, K. Resistance training combined with bench-step aerobics enhances women's health profile. Med Sci Sports Exerc 33: 259-269, 2001

28. Kraemer, WJ, Patton, SE, Gordon, E, Harman, MR, Deschenes, K, Reynolds, RU, Newton, N, and Travis-Triplett, JE. Compatibility of high-intensity strength and endurance training on hormonal and skeletal muscle adaptations. J Appl Physiol (1985) 78: 976-989, 1995.

29. Leveritt, M, Abernethy, PJ, Barry, BK, and Logan, PA. Concurrent strength and endurance training: The influence of dependent variable selection. J Strength Cond Res 17: 503-508, 2003.

30. Linthorne, NP. Analysis of standing vertical jumps using a force platform. Am J Phys 11: 1198-1204, 2001.

31. Marfell-Jones, M, Olds, T, Stewart, A, and Carter, L. International Standards for Anthropometric Assessment. Potchefstroom, South Africa: ISAK, 2006.

32. Marta, CC, Marinho, DA, Barbosa, TM, Carneiro, AL, Izquierdo, M, and Marques, MC. Effects of body fat and dominant somatotype on explosive strength and aerobic capacity trainability in prepubescent children. J Strength Cond Res 27: 3233-3244, 2013.

33. Marta, CC, Marinho, DA, Barbosa, TM, Izquierdo, M, and Marques, MC. Effects of concurrent training on explosive strength and VO $(2 \max )$ in prepubescent children. Int J Sports Med 34: 888896, 2013.

34. Mayhew, JL, Ware, JS, Johns, RA, and Bemben, MG. Changes in upper body power following heavy-resistance strength training in college men. Int J Sports Med 18: 516-520, 1997.

35. McCarthy, JP, Agre, JC, Graf, BK, Pozniak, MA, and Vailas, AC. Compatibility of adaptive responses with combining strength and endurance training. Med Sci Sports Exerc 27: 429436, 1995.

36. McGawley, $\mathrm{K}$ and Andersson, PI. The order of concurrent training does not affect soccer-related performance adaptations. Int J Sports Med 34: 983-990, 2013. 
37. Moazzami, M and Khoshraftar, N. The effects of a short time training program on physical fitness in female students. Proced Soc Behav Sci 15: 2627-2630, 2011.

38. Robineau, J, Babault, N, Piscione, J, Lacome, M, and Bigard, AX. The specific training effects of concurrent aerobic and strength exercises depends on recovery duration. J Strength Cond Res 30 : 672-683, 2016.

39. Santos, A, Marinho, DA, Costa, AM, Izquierdo, M, and Marques, MC. The effects of concurrent resistance and endurance training follow a detraining period in elementary school students. J Strength Cond Res 26: 1708-1716, 2012.
40. Silva, RF, Cadore, EL, Kothe, G, Guedes, M, Alberton, CL, Pinto, SS, Pinto, RS, Trindade, G, and Kruel, LF. Concurrent training with different aerobic exercises. Int J Sports Med 33: 627-643, 2012.

41. Taipale, R, Mikkola, J, Nummela, A, Sorvisto, J, Nyman, K, Kyröläinen, $\mathrm{H}$, and Häkkinen, K. Combined strength and endurance session order: Differences in force production and oxygen uptake. Int J Sports Physiol Perform 10: 418-425, 2015.

42. Takeshima, N, Rogers, NL, Rogers, ME, Islam, MM, Koizumi, D, and Lee, S. Functional fitness gain varies in older adults depending on exercise mode. Med Sci Sports Exerc 39: 2036-2043, 2007. 